\title{
DESEMPENHO DO TRATOR AGRÍCOLA EM FUNÇÃO DO TIPO DE BIODIESEL (SOJA X MURUMURU)
}

Murilo Coelho Teodoro Neves ${ }^{1}$, Afonso Lopes ${ }^{2}$, Leomar Paulo de Lima ${ }^{3}$, Melina Cais Jejcic de Oliveira ${ }^{4}$, Gilberto Hirotsugu Azevedo Koike

\begin{abstract}
RESUMO
Biodiesel é um combustível obtido por meio da transesterificação de óleos vegetais e gorduras animais, possui caráter renovável e biodegradável. Em crescente uso, faz-se necessário ampliar as matérias primas disponíveis em várias regiões e estudar o efeito destas novas fontes na maquinaria agrícola. O presente trabalho teve objetivo de avaliar desempenho operacional e opacidade da fumaça do trator agrícola funcionando com biodiesel de soja e biodiesel de murumuru. O experimento foi conduzido no Departamento de Engenharia Rural, da UNESP/Jaboticabal. As proporções de mistura biodiesel/diesel foram: B0 (0\% de biodiesel e 100\% de diesel), B5 (5\% de biodiesel e $95 \%$ de diesel), B15 ( $15 \%$ de biodiesel e $85 \%$ de diesel), B25 (25\% de biodiesel e $75 \%$ de diesel), B 50 ( $50 \%$ de biodiesel e $50 \%$ de diesel), B75 ( $75 \%$ de biodiesel e $25 \%$ de diesel) e B100 (100\% de biodiesel e $0 \%$ de diesel). Os resultados evidenciaram aumento de 9,59 e $15,85 \%$ no consumo específico comparando B0 a B100 de murumuru e soja, respectivamente. O consumo de B100 de murumuru foi 6,91\% menor que B100 de soja. A opacidade da fumaça reduziu 53,54 e 26,10\% quando se trabalhou com biodiesel de murumuru e soja, respectivamente. A opacidade de B100 de murumuru foi $19,81 \%$ menor que B100 de soja.
\end{abstract}

Palavras-chave: biocombustível, consumo específico, ensaio de trator e opacidade da fumaça.

\section{ABSTRACT \\ PERFORMANCE OF AN AGRICULTURAL TRACTOR IN FUNCTION OF BIODIESEL TYPE (SOYBEAN X MURUMURU) IN SOIL PREPARATION}

Biodiesel is a fuel obtained by transesterification of vegetable oils and animal fats, presenting renewable and biodegradable characteristics. Due to its growing use, it is necessary to expand the raw materials available in various regions and to study the effect of these new sources on agricultural machinery. The objective of the present study was to evaluate operating performance and smoke opacity of a tractor operating with soybean biodiesel and murumuru biodiesel. The experiment was conducted at the Department of Rural Engineering, UNESP/Jaboticabal. Mixing ratios of biodiesel/diesel were B0 ( $0 \%$ of biodiesel and $100 \%$ of diesel), B5 ( $5 \%$ of biodiesel and $95 \%$ of diesel), B15 (15\% of biodiesel and $85 \%$ of diesel), B25 (25\% of biodiesel and $75 \%$ of diesel), B50 (50\% of biodiesel and $50 \%$ of diesel), B 75 ( $75 \%$ of biodiesel and $25 \%$ of diesel) and B100 (100\% of biodiesel and $0 \%$ of diesel). Results showed an increase of 9.59 and $15.85 \%$ in specific consumption when comparing B0 and B100 of murumuru and soybean, respectively. The consumption of B100 of murumuru was $6.91 \%$ lower than B100 of soybean. Smoke opacity decreased by 53.54 and $26.10 \%$ when working with murumuru and soybean biodiesel, respectively. The opacity of B100 of murumuru was $19.81 \%$ lower than $\mathrm{B} 100$ of soybean.

Keywords: biofuel, specific consumption, tractor test and smoke opacity

\section{Recebido para publicação em 18/06/2012. Aprovado em 21/03/2013.}

1 - Eng. Agrônomo e Doutorando em Agronomia - DER/FCAV-UNESP, Jaboticabal (SP), murilocoelho.tn@gmail.com

2 - Prof. Adjunto, Departamento de Engenharia Rural - DER/FCAV-UNESP, Jaboticabal (SP), Afonso@fcav.unesp.br

3 - Prof. (Licenciatura em Ciências Agrárias) - DER/FCAV-UNESP, Jaboticabal (SP), leomaragro@yahoo.com.br

4 - Eng. Agrônoma e Doutoranda em Agronomia - DER/FCAV-UNESP, Jaboticabal (SP), melina_cais@yahoo.com.br

5 - Eng. Mecânico Doutor (Consultor Autônomo) - gkoike@bol.com.br 


\section{INTRODUÇÃO}

Em evidente linha de expansão, o mercado de combustíveis encontra-se no patamar em que procura e oferta crescem em ritmos acelerados, porém o crescimento da demanda é maior. Tal fato, aliado ao caráter finito e praticamente não renovável das reservas de combustíveis fósseis, levará a possível redução na disponibilidade, com consequente elevação gradual dos preços. Nesse contexto, o biodiesel surge como fonte promissora para suprir as necessidades do mercado consumidor e também como marco regulatório na segurança do abastecimento.

O biodiesel é produzido a partir de gorduras animais e óleos vegetais transesterificados, sendo que dezenas de espécies vegetais presentes no Brasil são utilizadas na produção deste combustível, entre elas soja, dendê, girassol, babaçu, amendoim, mamona e pinhão-manso (ANP, 2012). Lopes (2006) conceituou biodiesel como "biocombustível renovável, biodegradável e produzido a partir de óleo vegetal ou gordura animal e álcool anidro na presença de um catalisador. Esse produto é indicado para motores de ignição por compressão, podendo ser utilizado como aditivo ou em substituição ao diesel. Dependendo do processo de produção, o biodiesel pode ser filtrado ou destilado, metílico ou etílico, produzido com óleo degomado ou residual", bem como de gordura animal.

O biodiesel é visto como possível solução para as incertezas e dúvidas do futuro energético, principalmente dos países em desenvolvimento. Devido a grande semelhança com o diesel, em termos de estrutura química e conteúdo de energia, o biodiesel é compatível com os motores diesel, uma vez que não necessita de modificações (LAM et al., 2009).

O uso do biodiesel reduz a emissão de poluentes para a atmosfera, assim como a transformação de óleo residual de frituras em combustível, e minimiza o efeito deste sobre o solo e cursos d'água (LOPES et al., 2008). O setor agrícola responde por grande parte das emissões de poluentes para atmosfera, uma vez que praticamente todo o sistema depende de combustíveis derivados do petróleo. Segundo relatório do Ministério de Minas e Energia (EPE, 2011), o Brasil consumiu, em 2010, mais de 40 milhões de toneladas equivalente de petróleo de diesel. deste montante, 5,7 milhões (14,25\%) foram empregados no setor agrícola.

Basha et al. (2009) evidenciaram que o uso de biodiesel resulta na redução significativa da emissão de gases do efeito estufa quando se compara a queima deste combustível com o diesel convencional. A utilização do biodiesel destilado em trator agrícola na operação de escarificação resultou em aumento de $15,5 \%$ no consumo horário volumétrico, $18,1 \%$ no consumo horário ponderal, $16 \%$ no consumo operacional $(\mathrm{ha} / \mathrm{h})$, e $18 \%$ no consumo específico de combustível em relação ao diesel (SORANSO et al., 2008).

O turbocompressor é utilizado para aperfeiçoar a combustão e, de acordo com Darici et al. (2010) apud Canli et al. (2010), a presença deste equipamento promove decaimento no lançamento de gases poluentes no meio ambiente, melhora o desempenho dos motores e reduz o consumo de combustível. Tais vantagens são decorrentes do aumento do fluxo de ar para dentro da câmara de combustão, aumentando a quantidade de oxigênio que participará da queima do combustível. O sistema permutador de calor, ou intercooler, é considerado incremento para o turbocompressor. Este reduz a temperatura e aumenta a massa de ar admitida, que por sua vez, amplia o número de moléculas de oxigênio aptas a participar do processo de combustão. Em trabalho realizado por Akici (1999) apud Canli et al. (2010), demonstrouse que o resfriamento do ar na admissão causa incremento na potência do motor em $15,78 \%$ e que a opacidade da fumaça e o consumo específico, reduziram em $9,5 \%$ e $3 \%$, respectivamente.

Para avaliar a viabilidade do biodiesel, tornase fundamental o conhecimento das características do funcionamento das máquinas com o novo combustível ou sua mistura com diesel, as quais podem ser conhecidas através de ensaios de desempenho. O presente trabalho teve o objetivo de avaliar opacidade da fumaça e desempenho de trator agrícola em função do tipo de biodiesel (soja e murumuru) e proporções de mistura com diesel.

\section{MATERIAL E MÉTODOS}

O experimento foi conduzido no Laboratório de Máquinas e Mecanização Agrícola - LAMMA, do Departamento de Engenharia Rural, da Universidade Estadual Paulista - UNESP, Câmpus de Jaboticabal. A área está situada lateralmente

\section{REVENG}

351-360p. Engenharia na Agricultura, ViçOSA - MG, V.21 N.4, Julho / AgOSTO 2013 
à Via de Acesso Prof. Paulo Donato Castellane, $\mathrm{km} \mathrm{5}$, possui localização geodésica definida pelas coordenadas $21^{\circ} 15^{\prime}$ ' latitude sul e $48^{\circ} 18^{\prime}$ ' longitude oeste, com altitude média de $570 \mathrm{~m}$. A região apresenta temperatura média anual de $22,2{ }^{\circ} \mathrm{C}$, precipitação média anual de $1.425 \mathrm{~mm}$, umidade relativa média de $71 \%$ e pressão atmosférica de 94,3 $\mathrm{kPa}$ (UNESP, 2011). O clima da região, segundo a classificação de Köeppen, é do tipo Cwa, definido como subtropical com inverno seco em transição para o Aw, tropical úmido, com estação chuvosa no verão e seca no inverno.

O solo da área experimental foi classificado como Latossolo Vermelho Eutroférrico típico, com relevo suave ondulado e declividade média de 3\%, conforme o Sistema Brasileiro de Classificação de Solos (ANDREOLI; CENTURION, 1999). O teor médio de água no solo no dia do ensaio, no perfil de $0,00-0,15$ e $0,15-0,30 \mathrm{~m}$ de profundidade, foi 11,2 e $13,4 \%$, respectivamente, segundo o método gravimétrico-padrão. A análise granulométrica da camada de 0,00-0,20 m para argila, silte, areia fina e areia grossa foi 51, 29, 10 e 10\%, respectivamente, sendo o mesmo classificado como textura argilosa.

Utilizou-se biodiesel de soja e biodiesel de murumuru. O óleo diesel interior, classificado de acordo com a resolução da ANP $\mathrm{N}^{\circ} 42$, de 16 de dezembro 2009 (ANP, 2009), tendo quantidade de enxofre total máxima de $1.800 \mathrm{mg} \mathrm{kg}^{-1}$ e massa específica de $860 \mathrm{~kg} \mathrm{~m}^{-3}$ adquirido na cidade de Jaboticabal - SP.

$\mathrm{O}$ trator utilizado nos testes foi da marca Valtra, modelo BM 125i, 4x2 com tração dianteira auxiliar (TDA), potência máxima no motor de $91,9 \mathrm{~kW}$ $(125 \mathrm{cv})$ a 2300 RPM (ISO1585), equipado com turbocompressor e intercooler, massa total de $7.000 \mathrm{~kg}$, distribuídos 40 e $60 \%$ nos eixos dianteiro e traseiro, respectivamente, relação massa/potência de $76 \mathrm{~kg} \mathrm{~kW}^{-1}$ (56 $\mathrm{kg} \mathrm{cv}^{-1}$ ) equipado com pneus $\mathrm{R} 1$, radial, 14.9-26 no eixo dianteiro e 23.1-30 no eixo traseiro, estando os referidos pneus calibrados conforme recomendação do fabricante.

O Trator de frenagem utilizado foi da marca Valmet, modelo 118-4, 4×2, com tração dianteira auxiliar (TDA), potência de $82,43 \mathrm{~kW}(112 \mathrm{cv})$ no motor a $2400 \mathrm{rpm}$, massa total de $7310 \mathrm{~kg}$, distribuídos $40 \%$ e $60 \%$ nos eixos dianteiros e traseiros, respectivamente, equipado com pneus 14.9-28 no eixo dianteiro e 23.1-30 no eixo traseiro.
Entre os ensaios, foi drenado todo o biodiesel não consumido dos depósitos, filtros e tubulações, evitando contaminar o ensaio seguinte. Além disso, após a troca do combustível, o motor permaneceu em funcionamento por dez minutos antes do início de cada ensaio.

$\mathrm{O}$ trator teste instrumentado com célula de carga, unidade de radar, sistema de aquisição de dados modelo CR23X e um protótipo medidor de consumo de combustível contendo três depósitos auxiliares para biodiesel, conforme descrito por Lopes (2006).

O trabalho foi dividido em dois ensaios. Ensaio - I realizado em condições de campo, com o intuito de avaliar o desempenho do trator. Ensaio - II estático, para medir a opacidade da fumaça do motor. Os experimentos foram divididos em tópicos, apresentados da seguinte forma: Ensaio I Desempenho do trator, e Ensaio II - Opacidade da fumaça do motor do trator.

No Ensaio - I, avaliou-se desempenho do trator através da aferição do consumo específico, ponderal e volumétrico. Para tal, previamente realizou-se um ensaio preliminar, com a finalidade de definir a carga correspondente ao esforço máximo, tecnicamente viável, que o trator de teste pôde tracionar. Ressalta-se que tal carga foi obtida por meio da combinação de marchas do trator de frenagem, em que a força resultante foi igual a 23 $\mathrm{kN}$.

O trator de frenagem, acoplado ao trator de teste por meio de um cabo de aço, formando um comboio, trabalhou desligado e engrenado, pois a única função era oferecer carga, mais uniforme possível, na barra de tração do trator teste, sendo a velocidade de trabalho e a carga necessária obtida por meio da combinação do câmbio em $4^{\mathrm{a}}$ marcha, no grupo L.

Em todas as parcelas, procurando estabilizar as determinações, o trator de teste iniciava o movimento $15 \mathrm{~m}$ antes da primeira baliza que demarcava o início da medição. Quando o referencial do trator, centro do rodado traseiro, coincidia com a primeira baliza, era acionado o sistema de aquisição de dados. O procedimento era interrompido quando se decorria os $30 \mathrm{~m}$ de comprimento da parcela, momento em que o referencial coincidia com a segunda baliza. 
O consumo de combustível foi medido, em cada parcela, em unidade de volume $(\mathrm{mL})$, obtendose o volume total de alimentação na entrada da bomba injetora e o volume total retornado, sendo o combustível consumido a diferença entre as duas medidas. De posse desses dados, determinaram-se consumo horário volumétrico, consumo horário ponderal e consumo específico.

Determinou-se também como a densidade do combustível varia em função da temperatura e da proporção de mistura de diesel e biodiesel. Para essa finalidade, utilizou-se de balança de precisão, manta aquecedora e termômetro digital. No momento das avaliações, a temperatura ambiente era superior ao menor limite de temperatura do ensaio, por isso a amostra do combustível foi submersa em gelo a fim de que a temperatura se reduzisse a $15^{\circ} \mathrm{C}$, que correspondia ao limite inferior do ensaio. A partir desse ponto, a amostra foi aquecida até atingir a temperatura de $70{ }^{\circ} \mathrm{C}$, limite máximo do ensaio. No início da determinação, a $15{ }^{\circ} \mathrm{C}$ mediu-se volume de $100 \mathrm{~mL}$, verificou-se a massa e, depois, foi monitorada a variação volumétrica referente ao acréscimo de cada $5{ }^{\circ} \mathrm{C}$. Tal procedimento foi repetido para as cinco proporções de misturas. Com base na análise de variância, os dados foram ajustados por meio do modelo de maior grau significativo. Esse procedimento originou um modelo quadrático, conforme a Equação 1 (LOPES et al., 2003):

$\mathrm{D}=-0,0095 \mathrm{~T}^{2}+0,00173 \mathrm{P}^{2}-0,0124 \mathrm{~T}+0,5723 \mathrm{P}-0,0016 \mathrm{~T} \mathrm{P}+851$

em que

$\mathrm{D}=$ densidade da mistura diesel interior e biodiesel $\left(\mathrm{kg} \mathrm{m}^{-3}\right)$; $\mathrm{T}=$ temperatura do combustível $\left({ }^{\circ} \mathrm{C}\right)$;

$\mathrm{P}=$ proporção de Biodiesel (\%).

Com base no volume consumido e no tempo de percurso em cada parcela, foi determinado o consumo horário volumétrico, conforme Equação 2:

$\mathrm{Chv}=\left(\frac{\mathrm{Va}-\mathrm{Vr}}{\mathrm{t}}\right) \quad 3,6$

em que

Chv $=$ consumo horário volumétrico $\left(\mathrm{L} \mathrm{h}^{-1}\right)$;
$\mathrm{Va}=$ volume do combustível de alimentação $(\mathrm{mL})$;

$\mathrm{Vr}=$ volume do combustível de retorno $(\mathrm{mL})$;

$\mathrm{t}=$ tempo de percurso na parcela (s);

$3,6=$ fator de conversão.

Para o cálculo do consumo horário ponderal, considerou-se a influência da densidade do combustível de alimentação e o retorno no momento do teste, conforme Equação 3:

$$
\text { Chp }=\frac{(\text { Va Dca }- \text { Vr Dcr })}{\mathrm{t}} 0,0036
$$

em que

Chp = consumo horário ponderal $\left(\mathrm{kg} \mathrm{h}^{-1}\right)$;

$\mathrm{Va}=$ volume do combustível de alimentação $(\mathrm{mL})$;

$\mathrm{Dca}=$ densidade do combustível de alimentação $\left(\mathrm{kg} \mathrm{m}^{-3}\right)$;

$\mathrm{Vr}=$ volume do combustível de retorno $(\mathrm{mL})$;

Dcr $=$ densidade do combustível de retorno $\left(\mathrm{kg} \mathrm{m}^{-3}\right)$;

$\mathrm{t}=$ tempo de percurso na parcela $(\mathrm{s})$;

$0,0036=$ fator de conversão.

Consumo específico é o consumo de combustível expresso em unidade de massa por unidade de potência requerida na barra de tração, conforme Equação 4:

$\mathrm{Ce}=\left(\frac{\mathrm{Chp}}{\mathrm{PB}}\right) 1000$

em que

$\mathrm{Ce}=$ consumo específico $\left(\mathrm{g} \mathrm{kW}^{-1} \mathrm{~h}^{-1}\right)$;

$\mathrm{Chp}=$ consumo horário ponderal $\left(\mathrm{kg} \mathrm{h}^{-1}\right)$;

$\mathrm{PB}=$ potência na barra de tração $(\mathrm{kW})$;

$1000=$ fator de conversão.

Ensaio - II: realizado de acordo com o método da aceleração livre, em que o motor é submetido ao regime de rotação, sendo este obtido com o acelerador no seu curso máximo, em que a potência desenvolvida é absorvida somente pela inércia dos componentes mecânicos do motor (embreagem, árvore primária da caixa de mudanças), uma vez que o veículo está estacionado. As medições de opacidade da fumaça são feitas em $\mathrm{K}$, que é o coeficiente de absorção de luz, e tem como unidade $\mathrm{m}^{-1}$ conforme estabelece o manual do fabricante (TECNOMOTOR, 2012).

\section{REVENG}


Ambos os ensaios foram realizados com delineamento experimental inteiramente casualizado, sendo os dados analisados em esquema fatorial $6 \times 2$, com três repetições, totalizando 36 observações. As combinações dos fatores foram sete proporções de mistura biodiesel/diesel (B0, B5, B25, B50, B75 e B100, em que a letra indica à presença de biodiesel e $\mathrm{O}$ número a percentagem de biodiesel no diesel). No ensaio de desempenho, cada parcela experimental possuía $40 \mathrm{~m}$ de comprimento e, entre si, na direção longitudinal, havia reservado um espaço de $15 \mathrm{~m}$ destinado à realização de manobras, tráfego de máquinas e estabilização do conjunto motomecanizado em cada tratamento.

Os dados foram tabulados e submetidos à análise de variância e ao teste de comparação de médias de Tukey, a 5\% de probabilidade, conforme recomendação de Banzatto Kronka (2006). Para consumo específico e opacidade da fumaça, utilizou-se da análise de variância para selecionar o modelo de equação de maior expoente significativo e que fosse mais adequado para explicar o comportamento dessas variáveis em função da proporção de biodiesel

\section{RESULTADOS E DISCUSSÃO}

Verifica-se no, Quadro 1, que o biodisel de murumuru apresentou menor consumo que o biodiesel de soja, sendo a diferença de 9,22\% e 9,02\% para consumo horário volumétrico e consumo horário ponderal, respectivamente. No Quadro 2, observa-se que o consumo específico do trator foi $6,91 \%$ menor quando trabalhou com B100 de murumuru, em comparação ao B100 de soja. As alterações no consumo de combustível, nas três observações realizadas, podem ser atribuídas à diferença no número de cetano entre as diversas fontes de biodiesel. De acordo com Tong et al. (2011), o biodiesel derivado de soja possui de 45 a 60 cetanos, enquanto aqueles derivados de palmeiras, podem ter de 58,3 a 70 cetanos.

Os resultados do consumo horário volumétrico
(Chv) e consumo horário ponderal (Chp) (Quadro 1) demonstram que não houve diferença significativa para essas variáveis quando se compara B0 com B100. Os resultados obtidos contradizem os dados encontrados por Camara (2009) e Oliveira (2012) que, ambos os autores trabalhando com trator VALTRA BM 100 turbo e contrapondo B0 e B100, observaram incremento no consumo horário volumétrico de $10,7 \%$ e $31,6 \%$, respectivamente. Segundo os autores, o aumento no consumo horário volumétrico ocorre em função do menor poder calorífico do biodiesel em relação ao diesel, desta forma, é necessário desprender maior quantidade de combustível para realizar a mesma quantidade de trabalho.

De acordo com os dados de consumo específico expressos no Quadro 2, observa-se que para proporção de mistura, quando comparado B0 e B100, o consumo aumentou 15,8 e 9,6\%, para biodiesel de soja e murumuru, respectivamente. Estas diferenças ocorrem devido a maior densidade do biodiesel quando comparado ao diesel, e também pode ser relacionada com o menor poder calorífico do biodiesel em relação ao diesel, conforme Castellanelli et al. (2008) e Murugesan et al. (2009).

Em suas pesquisas, alguns autores apontaram que o uso de combustível com $100 \%$ de biodiesel (B100), quando comparado com B0, provoca aumentos em maiores escalas no consumo específico. Tabile et al. (2009), trabalhando com diesel interior ( $2.000 \mathrm{mg} \mathrm{kg}^{-1}$ de enxofre), metropolitano (500 $\mathrm{mg} \mathrm{kg}^{-1}$ de enxofre) e biodiesel de mamona etílico destilado, observaram aumento de 38,3\% no consumo especifico. Oliveira (2012), trabalhando com o biodiesel de mamona etílico destilado, observou incremento de 31,6\%. Supõese que a menor razão de consumo encontrada seja em função do intercooler, pois, de acordo com Uzun (2010), o consumo específico de um motor diesel decai entre 3 e $12 \%$ quando o motor possui o intercooler, sendo admissível que o efeito diminutivo observado para o diesel aplique-se também para o biodiesel, dada as semelhanças químicas e físicas entre os dois combustíveis. 
Devido à interação ocorrida no consumo específico, os dados foram desdobrados e apresentados no Quadro 2.

O consumo específico médio em função do tipo de biodiesel e a proporção de mistura foram ajustados, resultando em modelos lineares para o biodiesel de murumuru e biodiesel de soja, conforme ilustrado na Figura 1.

No Quadro 3, encontram-se os resultados da opacidade da fumaça. Devido à interação ocorrida, os dados foram desdobrados e apresentados no Quadro 4.

Quadro 1. Síntese da análise de variância e teste de médias para a variável consumo horário volumétrico (Chv) e consumo horário ponderal (Chp) e consumo específico (Ce) em função das proporções de biodiesel

\begin{tabular}{|c|c|c|c|}
\hline Fatores & Chv & Chp & $\mathrm{Ce}$ \\
\hline & $\mathrm{Lh}^{-1}$ & $\mathrm{~kg} \mathrm{~h}^{-1}$ & $\mathrm{~g} \mathrm{~kW}^{-1} \mathrm{~h}^{-1}$ \\
\hline \multicolumn{4}{|c|}{ Tipo de biodiesel (TB) } \\
\hline Soja & $14,1 \mathrm{a}$ & $12,2 \mathrm{a}$ & $320 \mathrm{a}$ \\
\hline Murumuru & $12,8 \mathrm{~b}$ & $11,1 \mathrm{~b}$ & $301 \mathrm{~b}$ \\
\hline \multicolumn{4}{|c|}{ Proporção de Biodiesel (Bn) } \\
\hline B0 & $13,7 \mathrm{a}$ & $11,7 \mathrm{ab}$ & 291 \\
\hline B5 & $13,0 \mathrm{a}$ & $11,1 \mathrm{a}$ & 296 \\
\hline B25 & $13,3 \mathrm{a}$ & $11,4 \mathrm{ab}$ & 307 \\
\hline B50 & $13,2 \mathrm{a}$ & $11,4 \mathrm{ab}$ & 312 \\
\hline B75 & $13,9 \mathrm{a}$ & $12,1 \mathrm{~b}$ & 322 \\
\hline B100 & $13,7 \mathrm{a}$ & $12,2 \mathrm{~b}$ & 335 \\
\hline \multicolumn{4}{|l|}{ TESTE $F$} \\
\hline TB & $51,0447 * *$ & $45,3165 * *$ & $40,9097 * *$ \\
\hline $\mathrm{B}_{\mathrm{n}}$ & $2,3067^{\mathrm{NS}}$ & $4,8091 * *$ & $19,1601 * *$ \\
\hline $\mathrm{TBxB}_{\mathrm{n}}$ & $1,2280^{\mathrm{NS}}$ & 0,8385 NS & $2,6199 *$ \\
\hline C.V.(\%) & 4,81 & 4,84 & 3,33 \\
\hline
\end{tabular}

** significativo $(\mathrm{P}<0,01)$; *: significativo $(\mathrm{P}<0,05)$; NS: não significativo; C.V.: coeficiente de variação. Médias seguidas pela mesma letra minúscula na coluna, não diferem entre si, pelo teste de Tukey, a 5\% de probabilidade.

Quadro 2. Síntese do desdobramento da interação tipo e proporção de biodiesel para variável consumo específico $\left(\mathrm{g} \mathrm{kW}^{-1} \mathrm{~h}^{-1}\right)$

\begin{tabular}{crrrrrrr}
\hline \multirow{2}{*}{ Tipo de Biodiesel } & \multicolumn{7}{c}{ Proporção de Biodiesel } \\
\cline { 2 - 7 } & B0 & B5 & B25 & B50 & B75 & B100 \\
\hline Soja & $292 \mathrm{Aa}$ & $302 \mathrm{Aab}$ & $323 \mathrm{Abc}$ & $326 \mathrm{Acd}$ & $332 \mathrm{Acd}$ & $347 \mathrm{Ad}$ \\
Murumuru & $292 \mathrm{Aab}$ & $291 \mathrm{Aa}$ & $291 \mathrm{Ba}$ & $298 \mathrm{Bab}$ & $313 \mathrm{Bbc}$ & $323 \mathrm{Bc}$ \\
\hline
\end{tabular}

Médias seguidas de mesma letra maiúscula na coluna e minúscula na linha não deferem entre si, pelo teste de Tukey a $5 \%$ de probabilidade.

\section{REVENG}




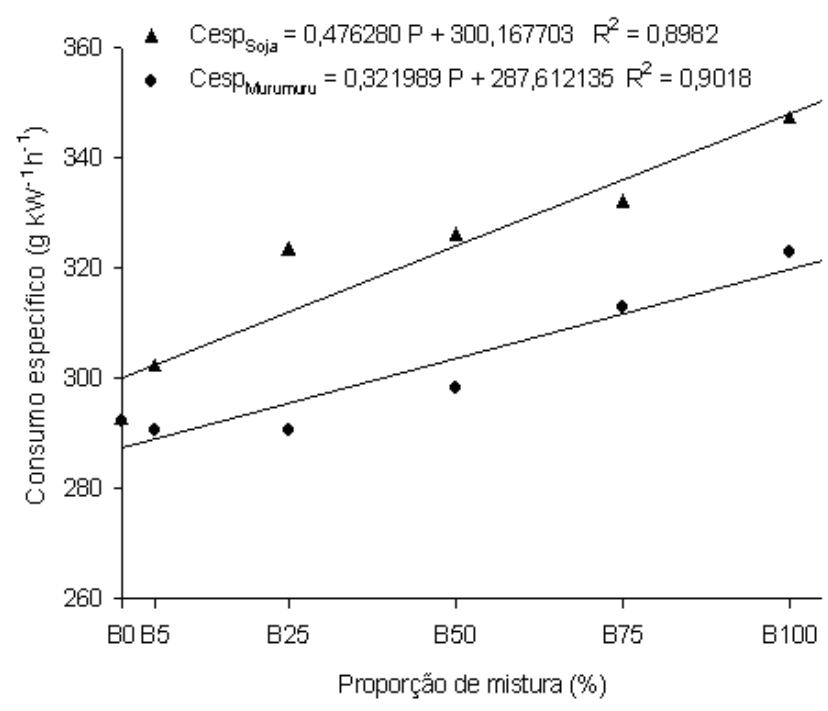

Figura 1. Modelo de regressão para o consumo específico (Cesp) em função do tipo e das proporções de mistura de biodiesel.

Quadro 3. Síntese da análise de variância e teste de médias para a variável opacidade da fumaça

Fatores $\quad$ Opacidade $\left(\mathrm{m}^{-1}\right)$

Tipo de biodiesel (TB)

Soja 2,12

Murumuru 1,70

\begin{tabular}{cc}
\hline Proporção de Biodiesel (Bn) & \\
B0 & 2,26 \\
B5 & 2,19 \\
B25 & 2,12 \\
B50 & 1,93 \\
B75 & 1,67 \\
B100 & 1,36 \\
\hline TESTE F & \\
TB & $1844,2320 * *$ \\
$B_{n}$ & $974,7652 * *$ \\
TBxB & $94,1066 * *$ \\
\hline C.V.(\%) & 2,87 \\
\hline
\end{tabular}

Médias seguidas pela mesma letra minúscula na coluna, não diferem entre si, pelo teste de Tukey, a 5\% de probabilidade. ** significativo $(\mathrm{P}<0,01)$; *: significativo $(\mathrm{P}<0,05)$; NS: não significativo; C.V.: coeficiente de variação.

Quadro 4. Síntese do desdobramento da interação tipo e proporção de biodiesel para a variável opacidade da fumaça $\left(\mathrm{m}^{-1}\right)$

\begin{tabular}{ccccccc}
\hline \multirow{2}{*}{ Tipo de Biodiesel } & \multicolumn{7}{c}{ Proporção de Biodiesel } \\
\cline { 2 - 7 } & B0 & B5 & B25 & B50 & B75 & B100 \\
\hline Soja & $2,26 \mathrm{Aa}$ & $2,36 \mathrm{Aa}$ & $2,32 \mathrm{Aab}$ & $2,16 \mathrm{Ac}$ & $1,95 \mathrm{Ad}$ & $1,67 \mathrm{Ae}$ \\
Murumuru & $2,26 \mathrm{Aa}$ & $2,02 \mathrm{Bb}$ & $1,93 \mathrm{Bb}$ & $1,70 \mathrm{Bd}$ & $1,39 \mathrm{Be}$ & $1,05 \mathrm{Bf}$ \\
\hline
\end{tabular}

Médias seguidas de mesma letra maiúscula na coluna e minúscula na linha não deferem entre si, pelo teste de Tukey a $5 \%$ de probabilidade. 
De acordo com o Quadro 4, nota-se que o biodiesel de soja apresentou redução na emissão de particulados quando houve adição de $50 \%$ de biodiesel de soja no diesel (B50). Comparando B0 e B100 o decréscimo na opacidade foi de $26,1 \%$. O biodiesel de murumuru reduziu a emissão quando houve adição de 5\% de biodiesel (B5) no diesel, sendo observada redução de $53,54 \%$ na opacidade da fumaça. Comparando os tipos de biodiesel, observa-se que em todas as proporções o biodiesel de murumuru emitiu menos material. Comparando tipo de biodiesel, observa-se que, trabalhando com biodiesel de murumuru, a opacidade da fumaça foi 19,81\% menor que biodiesel de soja.

Os dois biocombustíveis proporcionaram redução significativa na opacidade da fumaça. Esse fato é devido à combustão mais adequada quando se utiliza biodiesel, pois, no referido, há a presença de oxigênio livre na molécula, e, sendo assim, aumenta a eficiência na combustão. Resultados semelhantes foram encontrados por Lopes (2006) e Camara (2009).

Após analisados, os dados da opacidade da fumaça foram ajustados, resultando em um modelo linear para o biodiesel de murumuru e outro quadrático para biodiesel de soja, conforme ilustrado na Figura 2.

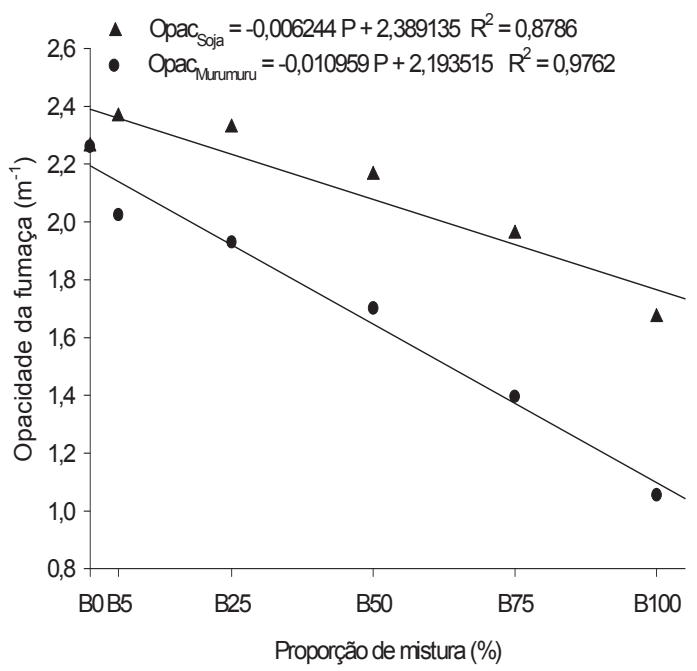

Figura 2. Modelo de regressão para opacidade da fumaça (Opac) em função do tipo e das proporções de mistura de biodiesel com diesel.

\section{CONCLUSÕES}

- As proporções de biodiesel no diesel não comprometeu o funcionamento do motor durante os testes;
- Trabalhando com biodiesel de murumuru o consumo horário volumétrico, consumo horário ponderal e consumo específico foram, respectivamente, $9,22,9,02$ e $6,92 \%$ menor que o consumo de soja;

- As proporções de mistura não resultaram diferença significativa no consumo horário volumétrico e consumo horário ponderal;

- Para consumo específico houve acréscimo de 15,85 e $9,6 \%$ para de biodiesel de soja e biodiesel de murumuru, respectivamente, quando comparado B0 e B100;

- Confrontando B0 com B100, a opacidade da fumaça reduziu 53,54 e $26,1 \%$ quando se trabalhou com murumuru e soja, respectivamente. A opacidade de B100 de murumuru foi $19,81 \%$ menor que B100 de soja.

\section{REFERÊNCIAS BIBLIOGRÁFICAS}

ANDREOLI, I., CENTURION, J.F. Levantamento detalhado dos solos da Faculdade de Ciências Agrárias e Veterinárias de Jaboticabal. In: CONGRESSO BRASILEIRO DE CIÊNCIA DO SOLO, 27, Brasília, 1999. Anais..., Brasília, Sociedade Brasileira de Ciência do solo, 1999. 32p. (T025-3 CD-ROM)

ANP - Agência Nacional do Petróleo, Gás Natural e Biocombustíveis. Resolução n.42 de 16 de dezembro de 2009. Disponível em: $<\mathrm{http}: / /$ nxt.anp.gov.br/nxt/getway.dll/leg/resolucoes anp/2009/dezembro/ranp\%2042\%20-\%202009. xml\#art16>. Acesso em 12 de fev.2012

ANP - Agência Nacional do Petróleo, Gás Natural e Biocombustíveis. O Biodiesel obrigatório.2012. Disponível em: <http://www. anp.gov.br/?pg $=46827 \& \mathrm{~m}=\& \mathrm{t} 1=\& \mathrm{t} 2=\& \mathrm{t} 3=\& \mathrm{t} 4=$ $\& \mathrm{ar}=\& \mathrm{ps}=\&$ cachebust $=1331852217628>$. Acesso em 15 fev.2012.

BANZATTO, D.A.; KRONKA, S.N. Experimentação agrícola. $4^{\mathrm{a}}$ ed. Jaboticabal: FUNEP, 2006. 237p.

BASHA, S.A., GOPAL, K.R., JEBARAJ, S. A review on biodiesel production, combustion, 
emissions and performance. Renewable and Sustainable Energy Reviews, v.13, p.1628-1634. 2009.

CAMARA, F.T. Biodiesel de dendê em trator agrícola: desempenho em função do tempo de armazenamento e da proporção de mistura na operação de preparo do solo. 2009. 92f. Tese (Doutorado em Agronomia). Faculdade de Ciências Agrárias e Veterinárias de Jaboticabal, Universidade Estadual Paulista "Julio de Mesquita Filho", Jaboticabal, 2009.

CASTELLANELLI, M.; SOUZA, S.N.M.; SILVA, S.L.; KAILER, E.K. Desempenho de motor ciclo diesel em bancada dinamométrica utilizando misturas diesel/biodiesel. Engenharia Agrícola, Jaboticabal, v.28, n.1, p.145-153. 2008.

CANLI, E.; DARICI, S.; OZGOREN, M.; Intercooler effect on conventional supercharging systems. International scientific conference, Novembro, 2010. Gabrovo. Disponível em: <http:// www.singipedia.com/content/2069-IntercoolerEffect-on-Conventional-SuperchargingSystems?langid=1 $>$. Acesso em: 20 de jan. de 2012.

EPE - Empresa de Pesquisas Energéticas do MinistériodeMinaseEnergia.Balanço Energético Nacional..2011. Disponível em: $<$ http://ben.epe. gov.br/BENRelatorioFinal2011.aspx>. Acesso em 14 fev. 2012.

LAM, M.K., TAN, K.T., LEE, K.T., MOHAMED, A.R. Malaysian palm oil: surviving the food versus fuel dispute for a sustainable future. Renew. Sustain. Energy, v.13, p.1456-1464. 2009.

LOPES, A.; FURLANI, C.E.A.; SILVA, R.P. Desenvolvimento de um protótipo para medição do consumo de combustível em tratores. Revista Brasileira de Agroinformática, Lavras, v.5, n.1, p.24-31. 2003.

LOPES, A. Biodiesel em trator agrícola: desempenho e opacidade. 2006, 158 f. Tese (Livre Docência em Agronomia) - Faculdade de Ciências Agrárias e Veterinárias de Jaboticabal, Universidade Estadual Paulista, Jaboticabal, 2006.
LOPES, A.; SENÔ, M.A.A.F.; CAMARA, F.T.; FURLANI, C.E.A.; SILVA, R.P.; CORTEZ, J.W. Biodiesel no Brasil: aspectos gerais e síntese da lesgislação. Atualidades Jurídicas, v.1, p.1-19, 2008.

MURUGESAN, A.; UMARANI, C.; SUBRAMANIAN, R.; NEDUNCHEZHIAN, N. Bio-diesel as an alternative fuel for diesel engines. Renewable and Sustainable Energy Reviews, Uttaranchal, v.13, n.3 ,p.653-662, 2009.

OLIVEIRA, M.C.J. Biodiesel de mamona em trator agrícola: Desempenho em função do período de armazenamento e da proporção biodieselldiesel. Dissertação (Mestrado em Agronomia)- Faculdade de Ciências Agrárias e Veterinárias de Jaboticabal, Universidade Estadual Paulista, Jaboticabal, 2012.

SORANSO, A.M.; GABRIEL FILHO, A.; LOPES, A.; SOUZA, E.G. De, DABDOUB, M.J.; FURLANI, C.E.A.; CAMRA, F.T. Desempenho dinâmico de um trator agrícola utilizando biodiesel destilado de óleo residual. Revista Brasileira de Engenharia Agrícola e Ambiental, Campina Grande, v.12, n.5, p.553-559. 2008.

TABILE, R.A.; LOPES, A.; DABDOUB, M.J.; CAMARA, F.T.;FURLANI, C.E.A.; SILVA, R.P. Biodiesel de mamona no diesel interior e metropolitano em trator agrícola. Engenharia Agrícola, Jaboticabal, v.29, n.3, p.412-423. 2009.

TECNOMOTOR, Tecnomotor Eletrônica do Brasil Ltda., OPACER TM 133 Opacímetro de amostragem. Manual de Operação. São Carlos, 2012. Ed. 07/01, 26p.

TONG, D.; HU, C.; JIANG, K.; LI, Y. Cetane Number Prediction of Biodiesel from the Composition of the Fatty Acid Methyl Esters. Journal of the American Oil Chemists, v.88, n.3, p.415-423 2011. Disponível em: < http://www. springerlink.com/content/e6277802615jn253>. Acesso em 12 jan. de 2012.

UNESP - UNIVERSIDADE ESTADUAL PAULISTA "JULIO DE MESQUITA FILHO" - 
CÂMPUS DE JABOTICABAL. Departamento de Ciências Exatas: Estação meteorológica Dados normais. 2011. Disponível em: <http:// www.exatas.fcav.unesp.br/estacao/est_tab_ meteor_01_02.htm>. Acesso em 12 dez. de 2011.
UZUN, A. The effects of intercooling on performance of a turbocharged diesel engine's specific fuel consumption with neural network. Scientific Research and Essays, Vol.5 (23), pp.3781-3793, 4 December, 2010. 